\title{
Characterization of the boundary layer at Dome C (East Antarctica) during the OPALE summer campaign
}

\author{
H. Gallée ${ }^{1}$, S. Preunkert ${ }^{1}$, S. Argentini ${ }^{2}$, M. M. Frey ${ }^{3}$, C. Genthon ${ }^{1}$, B. Jourdain ${ }^{1}$, I. Pietroni ${ }^{2}$, G. Casasanta ${ }^{2}$, \\ H. Barral ${ }^{1}$, E. Vignon ${ }^{1}$, C. Amory ${ }^{1}$, and M. Legrand ${ }^{1}$ \\ ${ }^{1}$ CNRS/UJF - Grenoble 1, Laboratoire de Glaciologie et Géophysique de l'Environnement, France \\ ${ }^{2}$ Istituto di Scienze dell' Atmosfera e del Clima (ISAC) - CNR, Italy \\ ${ }^{3}$ British Antarctic Survey, Natural Environment Research Council, Cambridge, UK \\ Correspondence to: H. Gallée (gallee@ lgge.obs.ujf-grenoble.fr)
}

Received: 20 October 2014 - Published in Atmos. Chem. Phys. Discuss.: 23 December 2014

Revised: 17 April 2015 - Accepted: 8 May 2015 - Published: 8 June 2015

\begin{abstract}
Regional climate model MAR (Modèle Atmosphérique Régional) was run for the region of Dome $\mathrm{C}$ located on the East Antarctic plateau, during Antarctic summer 2011-2012, in order to refine our understanding of meteorological conditions during the OPALE tropospheric chemistry campaign. A very high vertical resolution is set up in the lower troposphere, with a grid spacing of roughly $2 \mathrm{~m}$. Model output is compared with temperatures and winds observed near the surface and from a $45 \mathrm{~m}$ high tower as well as sodar and radiation data. MAR is generally in very good agreement with the observations, but sometimes underestimates cloud formation, leading to an underestimation of the simulated downward long-wave radiation. Absorbed short-wave radiation may also be slightly overestimated due to an underestimation of the snow albedo, and this influences the surface energy budget and atmospheric turbulence. Nevertheless, the model provides sufficiently reliable information about surface turbulent fluxes, vertical profiles of vertical diffusion coefficients and boundary layer height when discussing the representativeness of chemical measurements made nearby the ground surface during field campaigns conducted at Concordia station located at Dome C (3233 m above sea level).
\end{abstract}

\section{Introduction}

The aim of this paper is to evaluate MAR (Modèle Atmosphérique Régional) simulations during the OPALE campaign at Dome C in austral summer 2011-2012 (from late November 2011 to mid-January 2012), to support the inter- pretation of observations of tropospheric chemistry. A particular purpose is to characterize the behaviour and the vertical structure of the boundary layer at Dome $\mathrm{C}$ during this period.

A similar study was carried out previously above the East Antarctic plateau, based on summer-time observations at Kohnen station in Dronning Maud Land, albeit only with a more simplistic 1-D model (Van As et al., 2006).

Dome $\mathrm{C}$ is an area where observation and modelling of the boundary layer have already been performed due to its particular location (Swain and Gallée, 2006; Sadibekova et al., 2006; King et al., 2006; Gallée and Gorodetskaya, 2010; Genthon et al., 2010, 2013; Brun et al., 2011; Lascaux et al., 2011; Argentini et al., 2013; Pietroni et al., 2014). Furthermore, Dome C was recently selected as the test site for the next Gewex Atmospheric Boundary Layer Studies (GABLS4) model intercomparison (see http://www. cnrm.meteo.fr/aladin/meshtml/GABLS4/GABLS4.html). In spite of its remote location, Concordia station, operated yearround, is logistically well supported for a number of reasons. Dome $\mathrm{C}$ had been chosen as part of the EPICA project for drilling the ice core with the longest climate chronology ever recorded, allowing one to study the climate of the last eight glacial cycles (EPICA community members, 2004). The EPICA project initiated extensive meteorological observations at Dome $\mathrm{C}$, in order to establish, among other things, the relationship between local and global climate. Therefore, setting up a regional model at the Dome $\mathrm{C}$ drilling site enables one (i) to assimilate large-scale meteorological conditions and (ii) to simulate local atmospheric conditions, which contributes to establishing this relationship. The good 
management of logistics between the Concordia station and the Antarctic coast (Terre Adélie) and the low optical turbulence at Dome $\mathrm{C}$ also promoted the site for astronomical observations (see e.g. Swain and Gallée, 2006; Sadibekova et al., 2006). The main characteristic of meteorological conditions at Dome $\mathrm{C}$ is that turbulent conditions in the nearsurface atmosphere are only effective in a rather shallow layer, especially during night-time (Pietroni et al., 2014). During day-time the sensible heat fluxes are much larger than the latent heat fluxes, because of low temperatures and subsequently very low atmospheric moisture content (King et al., 2006). Consequently, the conditions for development of a well-mixed layer during daytime are optimal, in contrast to the situation in coastal Antarctica such as Halley station (King et al., 2006). This means that the simulation of summer case studies at Dome $\mathrm{C}$ will be very useful in validating the turbulence scheme of atmospheric models. Sodar and sonic anemometer measurements were done at the Concordia station to monitor the turbulent structure of the planetary boundary layer (PBL) in connection with the temperature inversion and to estimate the PBL height in the framework of the ABLCLIMAT (Atmospheric Boundary Layer Climate) project (Argentini et al., 2013).

The $45 \mathrm{~m}$ high tower built up at Concordia is also a very useful tool for observing such conditions (Genthon et al., 2010, 2013). Short-term meteorological simulations have already been done over Dome $\mathrm{C}$ with a coupled atmospheresnow model, focusing on the behaviour of the snow model (Brun et al., 2011). Long-term simulations of the Antarctic climate have also been done, with a focus on their behaviour at Dome C. Swain and Gallée (2006) and Lascaux et al. (2011) used respectively the limited area models MAR (without any reinitialization of meteorological variables) and Meso-NH to compare the optical properties of the atmosphere at Dome $\mathrm{C}$ with those of other potential Antarctic sites for astronomical observations using a large telescope. Gallée and Gorodetskaya (2010) validated MAR for winter conditions, emphasizing the difficulty in accurately simulating the downward long-wave radiation and proposing to include the influence of small airborne snow particles in the parameterization of the radiation transfer. MAR has also been used to provide information on the atmospheric turbulence at Dome $\mathrm{C}$ in summer, which appears to very significantly control the vertical flux and concentration profiles of numerous atmospheric chemical species (Legrand et al., 2009; Kerbrat et al., 2012; Dommergue et al., 2012; Frey et al., 2013). Finally, 2 years of observations at the Dome $\mathrm{C}$ tower were used to compare a long-term simulation of MAR with ECMWF analyses, showing the interest in representing the atmosphere with a fine vertical resolution (Genthon et al., 2013). Here we go a step further by evaluating in detail the model for summer conditions during the OPALE campaign.

The general motivation of the present research is to provide tools from a meteorological point of view for future campaigns dedicated to investigating the chemical composi- tion of the Antarctic boundary layer above the East Antarctic plateau. Thus, the first objective of this paper is to evaluate a meteorological model that is capable of simulating transport and that can be coupled to a chemical routine.

The second objective of the paper is to provide key physical parameters of the atmospheric boundary layer for the interpretation of data gained during the OPALE campaign as detailed in companion papers (see Legrand et al., 2014; Kukui et al., 2014; Frey et al., 2014; Preunkert et al., 2014). Transport processes are not considered during the 2011-2012 OPALE campaign and we will focus on situations characterized by an atmospheric circulation localized over the Antarctic plateau, where chemical properties of the air are rather homogeneous from one point to another. This means that from a meteorological point of view atmospheric turbulence plays the most important role in the fate of atmospheric $\mathrm{NO}_{x}$, $\mathrm{HONO}, \mathrm{HCHO}$, or $\mathrm{H}_{2} \mathrm{O}_{2}$ emitted by the snow pack. Key parameters are surface turbulent fluxes and the height of the boundary layer, which is determined by vertical turbulent diffusion. These parameters are used in companion papers to determine the contribution of turbulence to the concentration of key atmospheric species emitted from the surface, driving the oxidant budget in the near-surface atmosphere at Dome C. MAR turbulent vertical diffusion coefficients are used by Preunkert et al. (2014) and the uncertainty of the latter in HCHO mixing ratios is discussed. Legrand et al. (2014) also use the same MAR outputs to force their 1-D box model to simulate HONO mixing ratios. Kukui et al. (2014) performed similar calculations using the same MAR output. Frey et al. (2014) use MAR boundary layer heights to determine when they may apply the Monin-Obukhov similarity theory for calculating the turbulent fluxes of $\mathrm{NO}_{x}$ in the surface boundary layer. Other parameters like cloud cover and wind direction are considered for chemical analyses. For example, situations with an overcast sky were not considered, nor situations for which the wind direction is from Concordia station, since the air is then contaminated by pollutants emitted by the station. Sunny sky conditions were preferred since the assumption of a similar downward short-wave (DSW) radiation from sunny day to sunny day may be made. From a meteorological point of view, these criteria also allow us to avoid most of the situations for which clouds are underestimated by MAR, leading to erroneous behaviour of the surface energy budget, and subsequently of atmospheric turbulence, as explained by Legrand et al. (2014). Fortunately, such behaviour of MAR allows us to analyse the best part of the simulation, which corresponds to the same days for which the analysis of chemical species is the easiest.

The remainder of the paper is divided into four parts. The experimental set-up and the main characteristics of the MAR model are described in Sects. 2 and 3. The fourth section is dedicated to the evaluation of the model, looking in particular at the impact of the simulated radiative transfer on the surface atmospheric energy budget and atmospheric turbulence. 


\section{Meteorological observations}

\subsection{ISAC (Istituto di Scienze dell' Atmosfera e del Clima)}

One-year in situ turbulence and radiation measurements, as well as sodar observations, were carried out at the Concordia station from December 2011 up to December 2012 as part of the ABLCLIMAT project (Argentini et al., 2013).

The SL sodar (surface-layer sodar, Argentini et al., 2011) is an improved version of the sodar described by Argentini and Pietroni (2010), with the possibility of zooming into the atmospheric surface-layer thermal turbulent structure. With the SL sodar, the PBL height $h$ is estimated following Casasanta et al. (2014). During convective conditions, $h$ was determined as the height above the zone of weak backscattered intensity of the acoustic waves emitted by the sodar. Under stable conditions, $h$ was retrieved either from the minimum of the first derivative of the backscattered signal, or from its maximum curvature.

Measurements of turbulence were made with a Metek USA-1, a three-axis sonic thermo-anemometer (sampling frequency of $10 \mathrm{~Hz}$ ) installed on a $3.5 \mathrm{~m}$ mast. The heat and momentum fluxes are estimated using the eddy covariance method. The long-wave and short-wave radiation components (up and down) were measured with a Kipp \& Zonen CNR1 radiation sensor. This instrument combined two CM3 pyranometers for downward and upward broadband short-wave radiation flux (spectral range $305-2800 \mathrm{~nm}$ ) and two CG3 pyrgeometers for downward and upward broadband long-wave radiation flux (spectral range 5-50 $\mu \mathrm{m}$ ). Pyrgeometers and pyranometers were installed $1.5 \mathrm{~m}$ above the snow surface.

\subsection{LGGE (Laboratoire de Glaciologie et de Géophysque de l'Environnement)}

Meteorological measurements were made on a $45 \mathrm{~m}$ tower at Dome C since 2008 (Genthon et al., 2010). Wind, temperature and moisture are monitored at six levels from near the surface $(3.5 \mathrm{~m})$ to near the top of the tower $(42.1 \mathrm{~m})$. The instruments occasionally fail due to the extreme weather conditions at Dome C (extreme low temperatures, frost deposition); however, the data record is almost continuous since 2009 and the instruments work generally quite well in summer (Genthon et al., 2013). Genthon et al. (2011) have demonstrated that a bias to warmer temperatures affects measurements in Antarctica in cases of weak winds if conventional passively (wind) ventilated radiation shields are used to protect solid state thermometers (e.g. the ubiquitously used platinum thermistors) from solar radiation. To overcome this problem, the temperature measurements on the tower at Dome $\mathrm{C}$ are made in aspirated shields. Further details of the profiling set-up, instrumentation and results obtained so far can be found in Genthon et al. (2010, 2013).

\subsection{BAS (British Antarctic Survey)}

Measurements of turbulence are made with a Metek USA-1, a three-axis sonic thermo-anemometer (sampling frequency of $25 \mathrm{~Hz}$ ) mounted on a mast $4 \mathrm{~m}$ above the snow surface. The mast was set up in the clean-air sector at about $1.2 \mathrm{~km}$ distance from the $45 \mathrm{~m}$ meteorology tower (map in Frey et al., 2013), at the site where the chemical trace gas species were measured during the OPALE campaign. Atmospheric boundary layer parameters such as friction velocity $u_{*}$ and Monin-Obukhov length were computed from the three-dimensional wind components $(u, v, w)$ and temperature (Frey et al., 2014, this issue). Processing in $10 \mathrm{~min}$ blocks included temperature cross-wind correction and a double coordinate rotation to force mean w to zero (Kaimal and Finnigan, 1994; Van Dijk et al., 2006).

\section{Description of MAR}

An overview of the MAR regional climate model is given here, focusing on the description of the turbulence scheme. A more complete description can be found in Gallée and Schayes (1994), Gallée (1995) and Gallée et al. (2013).

MAR atmospheric dynamics are based on the hydrostatic approximation of the primitive equations. This approximation is correct when the vertical extent of the circulation (here the drainage flow) remains much smaller than the size of the grid (here $20 \mathrm{~km}$ ). Nevertheless, it should be noted that non-hydrostatic processes may be responsible for a weak deceleration of the katabatic flow (Cassano and Parish, 2000). The vertical coordinate is the normalized pressure, with the model top situated at the $1 \mathrm{~Pa}$ pressure level. Parameterization of turbulence in the surface boundary layer is based on the Monin-Obukhov similarity theory (MOST) and is completed by taking into account the stabilization effect by the blowing snow flux, as in Gallée et al. (2001) (see also Wamser and Lykossov, 1995). Turbulence above the suface boundary layer is parameterized using the local $E-\varepsilon$ model, consisting of two prognostic equations for turbulent kinetic energy and its dissipation. The prognostic equation of dissipation allows one to relate the mixing length to local sources of turbulence and not only to the surface. The $E-\varepsilon$ model used here has been adapted to neutral and stable conditions by Duynkerke (1988) and revised by Bintanja (2000), who included a parameterization of the turbulent transport of snow particles that is consistent with classical parameterizations of their sedimentation velocity. The influence of changes in the water phase on the turbulence is included following Duynkerke and Driedonks (1987). The relationship between the turbulent diffusion coefficient for momentum and scalars (Prandtl number) is dependent on the Richardson number, according to Sukoriansky et al. (2005).

Prognostic equations are used to describe five waterrelated parameters (Gallée, 1995): specific humidity, cloud 
droplets, ice crystals, raindrops and snow particles. A sixth equation has been added describing the number of ice crystals, and the influence of hydrometeors on air-specific mass is included in the model (Gallée et al., 2001). This allows us to account for the influence of the weight of eroded particles on atmospheric flow dynamics by representing the pressure gradient force as a function of air density rather than of potential temperature only.

The radiative transfer through the atmosphere is parameterized following Morcrette (2002) and is the same as the one used in ERA-40 re-analyses. As blowing snow particles are small (Walden at al., 2003), they may have an impact on the radiative transfer. The influence of snow particles on atmospheric optical depth is also included in the MAR model (Gallée and Gorodetskaya, 2010).

Surface processes are modelled using the "soil-ice-snowvegetation-atmosphere transfer" scheme (SISVAT, De Ridder and Gallée, 1998; Gallée et al., 2001; Lefebre at al., 2005; Fettweis et al., 2005). The influence of snow erosion / deposition on surface roughness $\left(z_{0}\right)$ is taken into account by allowing the aerodynamic roughness length to increase linearly as a function of the wind speed at $10 \mathrm{~m}$ above the ground level (a.g.l.) $\left(V_{10}\right)$, when $V_{10}>6 \mathrm{~m} \mathrm{~s}^{-1}$. The timescale for sastrugi formation is assumed to be half a day, as suggested by Andreas (1995), and the asymptotic value of the surface roughness length $z_{0}$ may increase linearly as a function of the wind speed $V\left(z_{0, \lim }=1.5 \mathrm{~mm}\right.$ for $V=10 \mathrm{~m} \mathrm{~s}^{-1}$; note that the friction velocity corresponding to $V=10 \mathrm{~m} \mathrm{~s}^{-1}$ is generally slightly greater than $0.5 \mathrm{~m} \mathrm{~s}^{-1}$ ). $z_{0}$ is allowed to decrease when precipitation occurs without wind erosion of the snow. Indeed, the newly deposited snow progressively buries the sastrugi. Andreas et al. (2005) found values of $z_{0}$ ranging between approximately $10^{-4}$ and $100 \mathrm{~mm}$, for friction velocities no greater than $0.6 \mathrm{~m} \mathrm{~s}^{-1}$. King and Anderson (1994) observed at Halley for compacted, sintered firn with some sastrugi, i.e. for similar snow properties as encountered at Dome C, a $z_{0}$ value of $(5.6 \pm 0.6) \times 10^{-5} \mathrm{~m}$. The scatter of $z_{0}$ is very high and is explained by the high dependency of $z_{0}$ on sastrugi history. Our parameterization includes that effect in a simple way, and is calibrated to obtain the best simulation of the wind speed. Note that the snow surface albedo depends on the snow properties (dendricity, sphericity and size of the snow particles) and solar zenithal distance, but not on sastrugi or sastrugi orientation.

\section{Evaluation of MAR}

We here used the 3-D version of MAR in order to take into account the influence of drainage winds on mass divergence at Dome $\mathrm{C}$ and consequently on subsidence and thinning of the boundary layer at the dome. In addition, this allows one also to account for a possible influence of the inversion wind circulation over the Dome $\mathrm{C}$ area, as suggested by Pietroni et al. (2014). The MAR domain is represented in Fig. 1. The

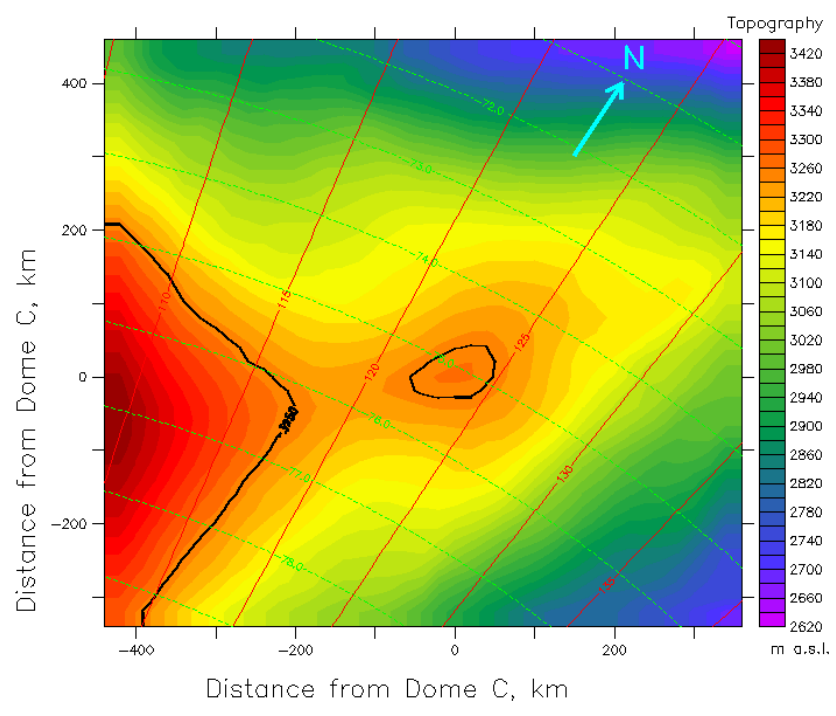

Figure 1. The MAR integration domain and topography. The solid line refers to the $3250 \mathrm{~m}$ isocontour.

horizontal grid size is $20 \mathrm{~km}$ and the vertical discretization in the lower troposphere is $2 \mathrm{~m}$, with 60 levels. The vertical resolution decreases with altitude above $32 \mathrm{~m}$ a.g.l., reaching $50 \mathrm{~m}$ at $300 \mathrm{~m}$ a.g.l. and $400 \mathrm{~m}$ at $3000 \mathrm{~m}$ a.g.l. In parallel, MAR was also run with a vertical grid spacing of $1 \mathrm{~m}$ in the lower levels, without any significant change in the results. Taking advantage of the higher vertical resolution near the surface, the output of this latter model run was used to discuss the behaviour (in particular the diurnal cycles) of different atmospheric components such as e.g. HONO, $\mathrm{ROH}, \mathrm{NO}_{x}$, and $\mathrm{HCHO}$, measured near the surface during the OPALE campaign (Legrand et al., 2014; Kukui et al., 2014; Frey et al., 2014; Preunkert et al., 2014).

The MAR model is nested into European re-analyses ERA-Interim (Dee et al., 2011). A relaxation zone of five grid points is prescribed at each lateral boundary (Marbaix et al., 2003) and model variables are nudged to the re-analysed variables in the upper six layers, i.e. above $13 \mathrm{~km}$ a.g.l. at Dome C. As the OPALE campaign took place from early December 2011 until mid-January 2012, MAR was run over 3 months (from 1 November 2011 until 31 January 2012). The model variables are assumed to adapt to Dome $\mathrm{C}$ conditions during the first simulated month (i.e. November 2011). The snow pack is initialized with a density of $300 \mathrm{~kg} \mathrm{~m}^{-3}$ and the assumption of the presence of small grains, which results in a slightly decreased initial albedo (close to 0.79 at noon), compared to the value $(0.80-0.81)$ estimated by Brun et al. (2011). Note that the albedo would have been more underestimated if sastrugi orientation had been taken into account (Wendler and Kelley, 1988). However, no observation of sastrugi has been made during the OPALE campaign. Our analysis focuses on the period between 12 December 2011 
and 14 January 2012, when most of the OPALE observations were made.

\subsection{Cloud cover and surface energy budget}

A problem already encountered when running the model over Adélie Land (East Antarctica) is an underestimation of the cloud cover (but not always) and the subsequent underestimation (overestimation) of the downward long-wave (short-wave) radiation. As a consequence, an underestimation (overestimation) of air temperatures near the surface during night-time (day-time) results (Gallée et al., 2013).

In the following we will investigate to what extent this shortcoming also occurs in the MAR simulations at Dome C. We note first that MAR generally underestimates both the short-wave and long-wave downward radiations, with a bias of about 24.3 and $20.8 \mathrm{~W} \mathrm{~m}^{-2}$ respectively (Table 1 ). The influence of the former on the surface energy budget is nevertheless less important than that of the latter, because of the high value of the snow albedo.

Let us now examine the downward long-wave radiation and the air temperature near the surface (Fig. 2). Both observations and simulation exhibit rapid variations in the longwave downward radiation (LWD) (Fig. 2a). The correlation coefficient between the simulated LWD and cloud optical thickness is 0.79 for a 10 min time interval between each value of these variables, suggesting that cloud cover changes are responsible for most of these variations.

Figure $2 \mathrm{~b}$ compares the daily averaged bias (simulation minus observation) in the long-wave downward radiations (LWD) and air temperatures near the surface at Dome C. The former is generally underestimated, leading to the underestimation of the latter (see also Table 1). A significant correlation may be seen between both biases, even when the temperature bias may be positive, while the long-wave downward radiation bias remains negative. But the latter bias is partially compensated for by a slight positive bias in the absorbed solar radiation (Table 1), probably because of an underestimation of MAR snow surface albedo.

In contrast, the bias in the absorbed solar radiation may become negative, for example on 10 and 11 January 2012, when the bias in the long-wave downward radiation is almost zero and significant snowfall is simulated. The positive temperature bias on 31 December 2011 is probably due to an overestimation of the long-wave downward radiation by MAR.

Thus, as already observed along the Adélie Land coast (see Gallée et al., 2013), MAR underestimates cloud cover at Dome C, but not always. This underestimation is responsible for an underestimation of the downward long-wave radiation. As long-wave downward radiation plays a key role in the surface energy budget and the subsequent behaviour of turbulence near the surface, this point will be considered in the remainder of the paper. Concerning the application of MAR for the interpretation of the atmospheric chemistry
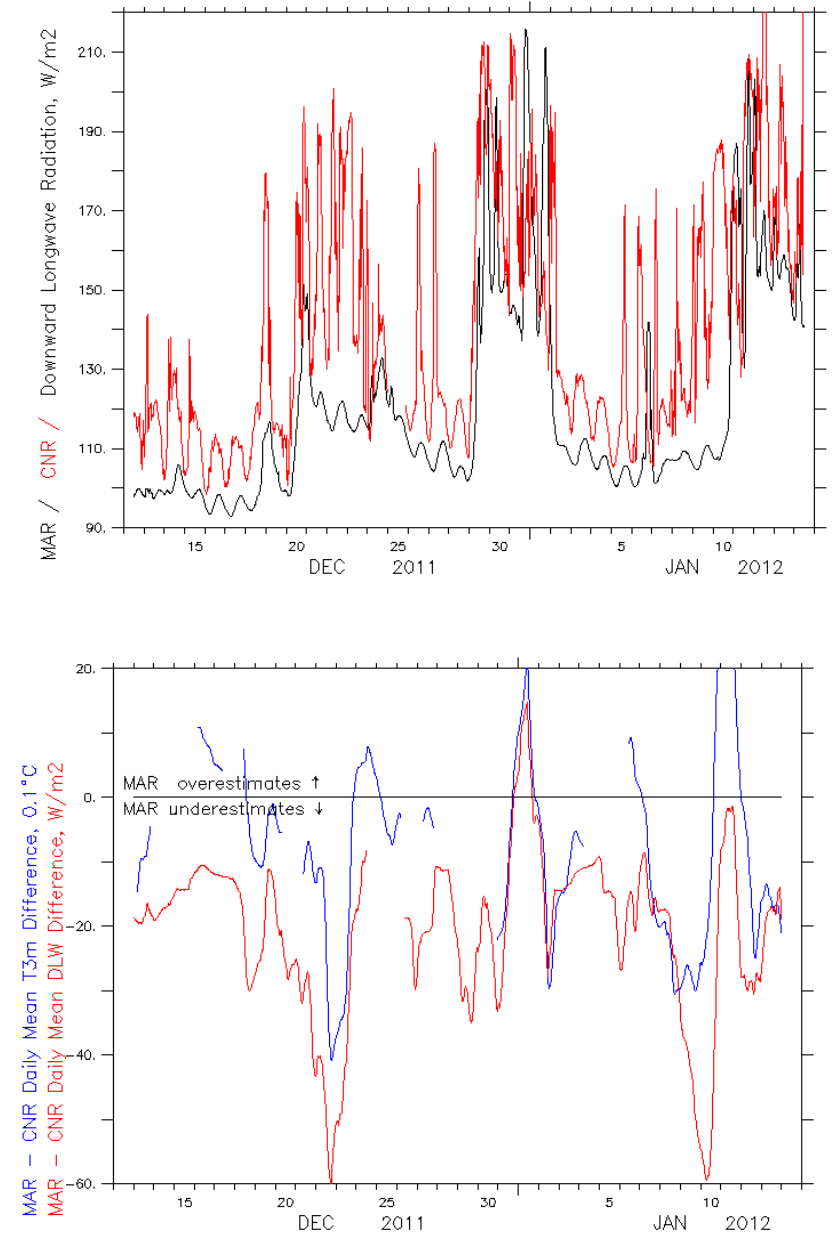

Figure 2. Top: long-wave downward radiation ( $\mathrm{LWD}, \mathrm{W} \mathrm{m}^{-2}$ ): simulation (dark line) and observation (red line). Data were averaged over an interval of $30 \mathrm{~min}$. Bottom: comparison between the daily averaged LWD bias (red line) and air temperature bias (blue line, units: $0.1^{\circ} \mathrm{C}$ ). Observations are those of the ISAC. MAR temperatures are averaged between $2 \mathrm{~m}$ and $4 \mathrm{~m}$ a.g.l. Gaps correspond to the absence of observations.

measured during OPALE, the underestimation of the cloud cover is generally not critical, since situations with an overcast sky were not considered in these model applications.

\subsection{Wind and temperature near the surface}

The performances of the simulated temperature and wind speed are summarized in Table 1 by the correlation between simulation and observation, the bias (simulation minus observation), the root mean square error (RMSE) and the efficiency statistical test $(E)$ proposed by Nash and Sutcliffe (1970):

$E=1-\mathrm{RMSE}^{2} / s^{2}$,

where $s$ and RMSE are respectively the standard deviation of the observations and the root mean square error of the sim- 
Table 1. Correlation coefficient, bias, RMSE (root mean square error) and efficiency statistical test of the simulated short-wave downward radiation (SWD), the short-wave absorbed radiation by the surface (SWA), the long-wave downward radiation (LWD), the temperature and the wind speed when compared to the observations made by ISAC (Istituto di Scienze dell' Atmosfera e del Clima) (third and fourth column), by LGGE (Laboratoire de Glaciologie et de Géophysique de l'Environnement) (at the tower, fifth column) and by BAS (British Antarctic Survey) (sixth column). Data were averaged over an interval of $30 \mathrm{~min}$.

\begin{tabular}{llrrrr}
\hline MAR & & ISAC & ISAC 3 m & Tower 3 m & BAS 4 m \\
\hline SWD & Bias & $-24.3 \mathrm{~W} \mathrm{~m}^{-2}$ & & & \\
SWA & Bias & $3.4 \mathrm{~W} \mathrm{~m}^{-2}$ & & & \\
LWD & Bias & $-20.8 \mathrm{~W} \mathrm{~m}^{-2}$ & & & \\
\hline Temperature & Corr. coeff. & 0.981 & 0.912 & 0.973 \\
& Bias & $-0.387{ }^{\circ} \mathrm{C}$ & $-0.642{ }^{\circ} \mathrm{C}$ & $-0.551{ }^{\circ} \mathrm{C}$ \\
& RMSE & $2.408^{\circ} \mathrm{C}$ & $2.778^{\circ} \mathrm{C}$ & $2.735^{\circ} \mathrm{C}$ \\
& E & 0.958 & 0.751 & 0.933 \\
\hline \multirow{2}{*}{ Wind speed } & Corr. coeff. & 0.865 & 0.872 & 0.856 \\
& Bias & & $-0.227 \mathrm{~m} \mathrm{~s}^{-1}$ & $-0.105 \mathrm{~m} \mathrm{~s}^{-1}$ & $0.440 \mathrm{~m} \mathrm{~s}^{-1}$ \\
& RMSE & $1.057 \mathrm{~m} \mathrm{~s}^{-1}$ & $0.949 \mathrm{~m} \mathrm{~s}^{-1}$ & $1.089 \mathrm{~m} \mathrm{~s}^{-1}$ \\
& E & 0.737 & 0.752 & 0.677 \\
\hline
\end{tabular}

ulated variable. Note that RMSE $=0$ implies $E=1$. An efficiency index greater than 0 also means that comparing the simulated variable with the corresponding observation provides a lower RMSE than that obtained when comparing it with its time average. A negative efficiency index means that the RMSE is higher than the standard deviation of the observations. Finally, this then suggests that a detailed model would not improve the results when compared to a simpler model providing an estimation of the variable averaged over the time period concerned.

It is found that the efficiency statistical test for temperature and wind speed is not lower than 0.677 for all comparisons (Table 1), giving us confidence in the respective time averages as well as in the fluctuations of these simulated variables.

For a more detailed examination of wind speed and temperature, the comparison between simulated and observed wind speeds at $3 \mathrm{~m}$ above the surface is shown in Fig. $3 \mathrm{a}$. The agreement is good, as also quantified by the efficiency $(0.737$, Table 1$)$. As can be seen in Fig. 3b, the agreement between the simulated and observed wind directions is also excellent. This behaviour indicates that the model is able to capture the atmospheric circulation at Dome $\mathrm{C}$ on the synoptic scale and is able to simulate the local circulation. Both observation and simulation reveal two preferential wind directions, one from the plateau (southerly winds) and the other from the ocean (northerly winds). A well-marked diurnal cycle is generally found in the wind speed, but does not exist in the wind direction. Wind speed peaks during the afternoon, when turbulent fluxes in the well-mixed layer are able to transport momentum downwards more efficiently. Wind speed is also generally stronger and may be faster than $6 \mathrm{~m} \mathrm{~s}^{-1}$ in the case of wind blowing from the north, except on 5-7 January 2012, when wind was blowing from the south. Note that the sim- ulation of a blowing snow event on 29 December is responsible for an increase in the simulated roughness length from an almost constant in time value of $0.05 \mathrm{~mm}$ to an almost constant in time value of $2 \mathrm{~mm}$. No significant change in the agreement between simulations and observations of the wind speed or of the friction velocity after this increase may be deduced from a look at Fig. 3. Consequently, it is difficult to determine whether the parameterization of the roughness length at Dome $\mathrm{C}$ is important for the simulation.

The simulated air temperature is also in good agreement with observations (Fig. 3c), although the simulated diurnal cycle is generally more pronounced than the observed one, especially for night-time (not shown for tower and BAS observations). The largest differences are found when simulations are compared with the observations made at the tower. Note that tower temperature measurements are performed in aspirated shields which have been demonstrated to avoid large warm biases with the most often used passively ventilated shields in cases of weak winds (Genthon et al., 2011). Since these are the only temperature measurements carried out in aspirated shields at Dome $\mathrm{C}$, they are (except for sonic measurements) the only ones which are unaffected by radiation biases.

Finally, the good behaviour of the simulated friction velocity (Fig. 3d) suggests that MAR simulates surface meteorological variables without compensating errors. From the previous analysis we have some confidence in the behaviour of the model in the surface boundary layer at Dome $\mathrm{C}$ during the OPALE observation period, but some discrepancies with the observations are found, even for sunny days. 

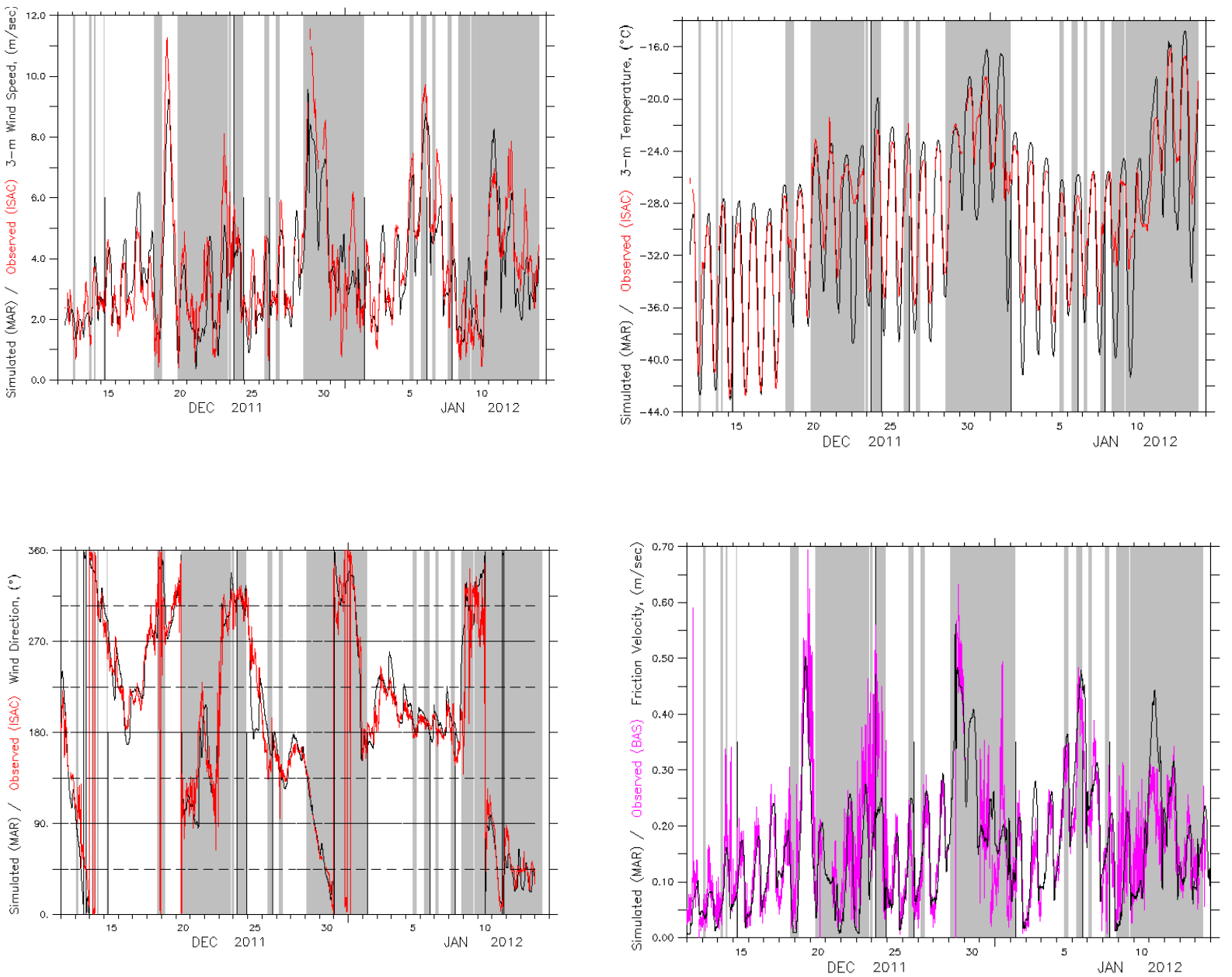

Figure 3. Simulation (dark line) of wind speed (top left), wind direction (top right), and air temperature (bottom left) at Dome C, $3 \mathrm{~m}$ a.s.1., compared with ISAC observations. Bottom right: simulation of friction velocity (dark line) compared with BAS observations (magenta line). Data were averaged over an interval of $30 \mathrm{~min}$. Shaded area indicates periods with DLW $>130 \mathrm{Wm}^{-2}$.

\subsection{Period between 26 and 28 December 2011}

In the following we will focus on the period between 26 and 28 December 2011, which is also included in the studies of Legrand et al. (2014), Kukui et al. (2014), Preunkert et al. (2014), and Frey et al. (2014). Moreover, this is the longest period for which we have estimations of the boundary layer height from sodar measurements. This period is characterized by winds coming from the high East Antarctic plateau and by an absence of clouds except between 09:00 and 15:00 LT on 26 December and between 04:00 and 11:00LT on 27 December, when the downward longwave flux (LWD) is relatively large in the observations. Unfortunately, MAR underestimates LWD at those times (see Sect. 4.1 and Fig. 2a).

In Fig. 4a we report on the behaviour of the simulated temperature and wind speed at the tower, between 3.5 and $42.1 \mathrm{~m}$ a.g.l. The simulation exhibits a marked diurnal cycle, with a strong temperature inversion during night-time and a well-mixed layer during day-time. During night-time a close link exists between the vertical temperature gradient and the vertical wind speed gradient. The vertical wind speed gradient is highest where temperature increase with height is strongest and the associated vertical stability is largest. Such behaviour is often referred to as a decoupling between the cold air near the surface and the warmer air above. This decoupling is also found in a change of the wind direction just above the turbulent layer. Convective mixing during day-time precludes this behaviour, and the vertical gradients of both temperature and wind speed are much smaller. Night-time decoupling and day-time mixing are also found in the observations, but with some differences due to the presence of clouds that the model was not able to simulate.

It is seen in Fig. 4b that the model simulates a warm bias on 26 December 2011 until 18:00 LT, except below $10 \mathrm{~m}$ a.g.l., until 6:00 LT. Probably the absence of simulated clouds is responsible for an overestimation of the surface absorbed solar radiation and the subsequent heating of the sur- 

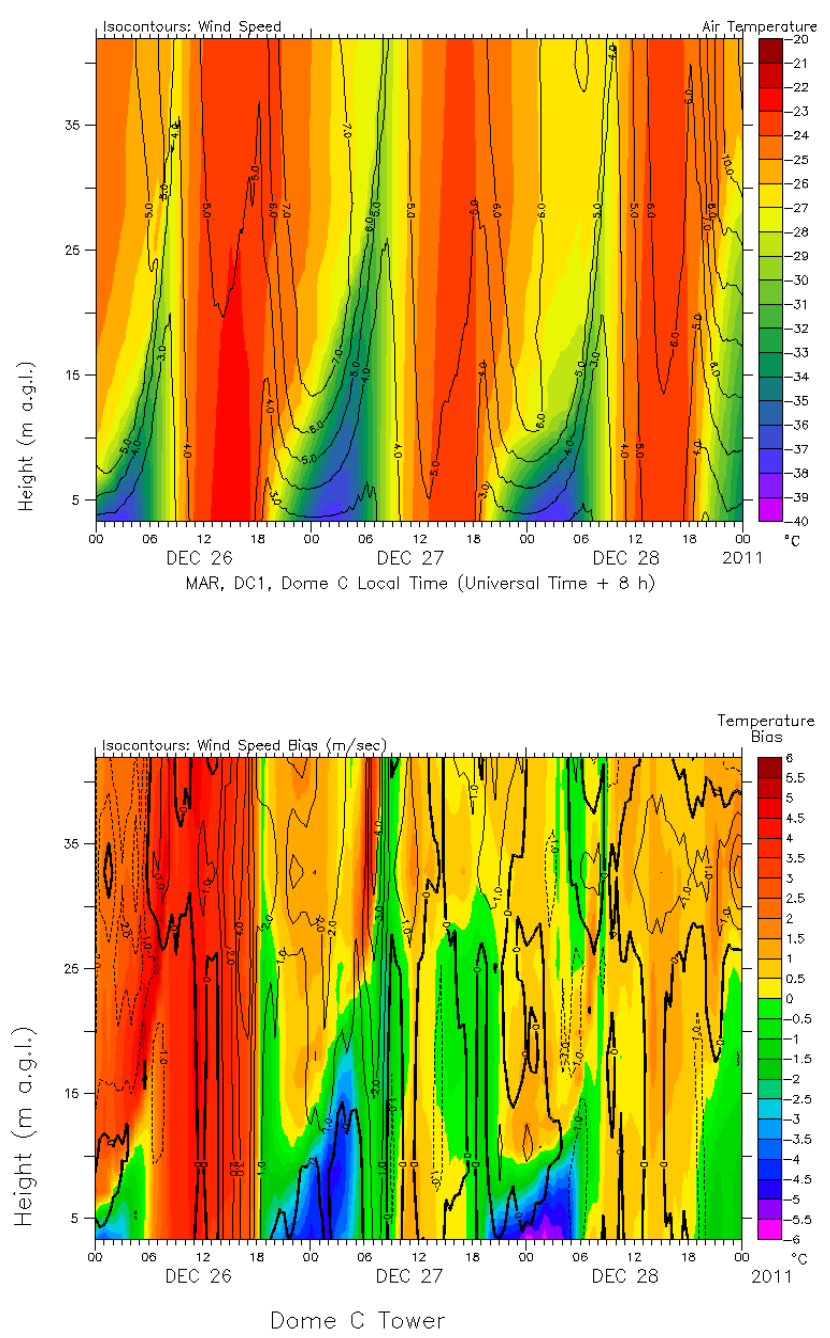

Figure 4. Temperature (colour) and wind speed (isocontours) at the Dome $\mathrm{C}$ tower, as a function of Local Time LT (Universal Time $\mathrm{UT}+8 \mathrm{~h}$ ) and height above the surface. (a) refers to the MAR simulation, (b) to simulation minus observation.

face. The heat excess is then transferred to the atmosphere through turbulent mixing. Note that the marked overestimation of the simulated absorbed solar radiation and air temperature is not repeated on 27 and 28 December 2011 in spite of the presence of clouds on 27 December in the morning. Nevertheless, temperature maxima are overestimated by roughly 1 to $1.5^{\circ} \mathrm{C}$, both at the surface (not shown) and above.

Air temperatures on 27 and 28 December in the morning are significantly underestimated in the MAR simulations, especially on 28 December. The underestimation starts on the previous day around 18:00 LT. An underestimation of about $10 \mathrm{~W} \mathrm{~m}^{-2}$ or more is also found in the downward long-wave radiation (LWD), even in the absence of clouds (Fig. 2a). Simulated and observed turbulent fluxes are compared in Fig. 5. The simulated friction velocity is slightly underestimated by the MAR model during night-time, especially on
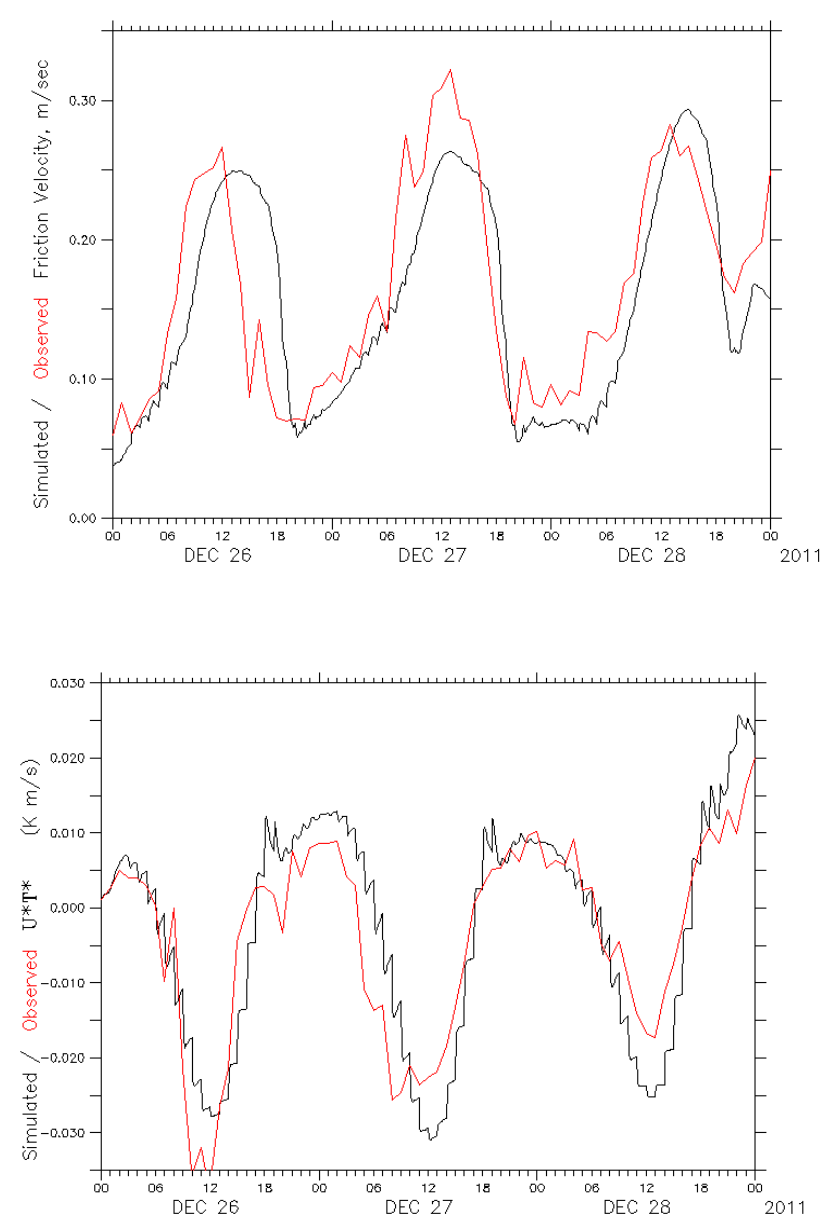

Figure 5. Surface turbulent fluxes at the Dome $\mathrm{C}$ tower, as a function of Local Time LT (Universal Time UT $+8 \mathrm{~h}$ ). Panel (a) refers to the friction velocity, and panel (b) to the sensible heat flux $u^{*} T^{*}$. The dark line is the MAR simulation, the red line the ISAC observations.

28 December, while the simulated downward turbulent heat flux is comparable to the observations or is slightly overestimated. Possibly the simulated surface turbulent heat flux would have been larger if the friction velocity had not been underestimated by the model at that time. Thus, MoninObukhov similarity theory is not a good candidate for explaining the underestimation of temperature near the surface. More precisely looking at the experiment with $1 \mathrm{~m}$ resolution, it is found that the weakening of the turbulent fluxes from 1 to $2 \mathrm{~m}$ amounts to slightly more than $20 \%$, a value that is larger than the usual departure from constancy generally accepted $(10 \%)$. More generally, temperature and wind speed at $2 \mathrm{~m}$ in the simulations with 1 and $2 \mathrm{~m}$ resolution near the surface have been compared. It has been found that when clear sky is observed they are not sensitive (differences no larger than 1.5 to $2^{\circ} \mathrm{C}$ or $1 \mathrm{~m} \mathrm{~s}^{-1}$ ) to the vertical resolution, even when in the simulation with $1 \mathrm{~m}$ resolution the turbulent fluxes between 1 and $2 \mathrm{~m}$ depart from the constancy by 


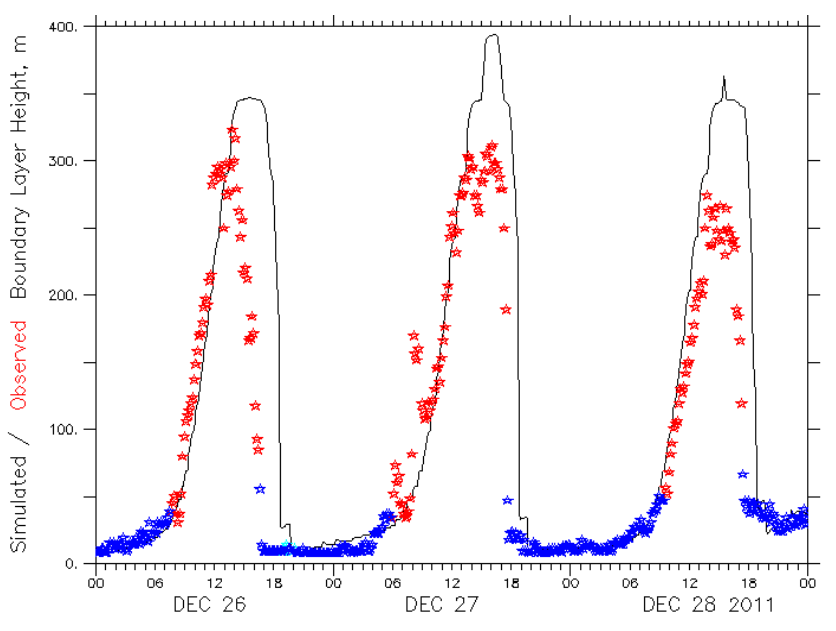

Figure 6. The boundary layer height at Dome $\mathrm{C}$ as a function of Local Time LT (Universal Time UT $+8 \mathrm{~h}$ ). Red (blue) stars: sodar observations during convective (stable) situations (Argentini et al., 2013). Dark line: MAR mixed layer depth, computed as the level where the turbulent kinetic energy amounts to $5 \%$ of the turbulent kinetic energy in the lowest layer of the model.

$30 \%$. In contrast, a slight overestimation of the air temperature above 10-15 ma.g.l. (Fig. 4b) could also result from an insufficient turbulent mixing by the $E-\varepsilon$ model during night-time, explaining also partly the underestimation of the air temperature near the surface. Finally, it could be argued that an initial underestimation of the air temperature near the surface may be responsible for an increased vertical stability above the surface boundary layer, reinforcing the decoupling between the lower troposphere and the atmosphere above, and being responsible for a possible underestimation of the boundary layer height. A possible leading role of an underestimation of LWD must be firmly established.

From Fig. 5 it is also found that MAR underestimates the upward turbulent heat flux during day-time, when observed clouds were not simulated (on 26 December around noon and on 27 December in the morning), while it overestimates it when clouds are not present, either in the observation or in the simulation (on 27 and 28 December during day-time). No definite explanation was found for the underestimation, but the overestimation may be related to overly high heating of the surface and an overestimation of the air temperature by the model (see Fig. 4b), suggesting that the overestimation of air temperature at that time is driven by the surface.

Biases in the simulated wind speed could sometimes be linked to biases in the simulated air temperature, but not always. An example of such a link in Fig. $4 \mathrm{~b}$ is a positive wind speed bias simulated between 15 and 18:00 LT on 26 December 2011. It could be associated with the positive bias in the downward short-wave radiation. At that time, the overestimated turbulent mixing could lead to an overestimated height of the turbulent layer and an overestimated downward transfer of momentum. Indeed, simulated wind speeds are larger than observations at the upper levels of the tower at that time (Fig. 4a) and the model overestimates the height of the wellmixed layer (Fig. 6). The bias in the wind speed decreases after 18:00 LT, especially below $25 \mathrm{~m}$ a.g.l. This is due to an increasing stability near the surface and the subsequent decoupling between the layer of air near the surface and the layer above. Wind speeds are still overestimated above up to the highest level of the tower, possibly because of an overestimated vertical extent of the residual mixed layer at that time.

Observations suggest the onset of a nocturnal jet after 18:00 LT, with a maximum of $7 \mathrm{~m} \mathrm{~s}^{-1}$ around $20 \mathrm{ma.g}$.l. around 22:00 LT. MAR also simulates a nocturnal jet at that time, but around $140 \mathrm{ma.g} .1$, and with a slightly stronger wind speed $\left(8 \mathrm{~m} \mathrm{~s}^{-1}\right)$ (not shown). This occurrence is consistent with a higher extent of the residual layer and may be the consequence of the sudden shutdown of the turbulent mixing at 18:00 LT at $140 \mathrm{~m}$ a.g.l. in the model (not shown), while the pressure gradient force (PGF) still contributes to an increase in the wind speed after that time. Such an evolution is typical for a convective mixed layer at the end of day-time, and is also observed at lower latitudes. The contribution of PGF to the acceleration of the wind starts to decrease after 20:30 LT. Since nocturnal low level jets arrived frequently during OPALE, the analysis of this process deserves some attention. Therefore, this topic will be addressed in a companion note by analysing a case study which is well simulated by the model (Gallée et al., 2015).

A small positive temperature bias seems also to occur at 06:00 LT on 27 December 2011 above $25 \mathrm{~m}$ a.g.l. Its behaviour is similar to that of 26 December, and it also occurs in conjunction with an underestimation of the cloud cover by the model and an earlier deepening of the well-mixed layer.

Finally, the sodar reveals an earlier peak and fall-off in boundary layer depth on 26 December than does the model (Fig. 6). This is due to clouds which are responsible for a strong decrease in SWD, while clouds are not simulated.

\section{Discussion and conclusion}

The MAR model has been set up over a domain covering Dome $\mathrm{C}$ during the OPALE campaign. The size of the domain is much smaller than the internal radius of deformation. As a consequence, the model solution is constrained in the free atmosphere by the one of the European re-analyses (ERA-Interim), but, as already pointed out by Lefebre et al. (2005), it is allowed to develop its own solution in the boundary layer. The simulation is characterized by a positive efficiency of wind and temperature over Dome C, given us confidence in its behaviour. In certain situations, MAR underestimates the downward long-wave radiation. When this problem occurs it is often linked to an underestimation of the cloud cover, and is one of the reasons which leads to an overestimation of the simulated amplitude of the diur- 
nal cycle of air temperatures. Another possible cause of this overestimation is the underestimation of heat transfer in the snow pack and an amplification of the subsequent decoupling between the atmosphere and the surface initiated by the underestimated LWD and heat conduction. Indeed, surface turbulent fluxes are well simulated, but discrepancies with the observations are found when the simulated downward long-wave flux is underestimated. Note that, since this underestimation of the LWD will also induce an error in the modelled temperatures, measured temperatures, which were available throughout the OPALE campaign, were used when interpreting the chemistry data (e.g. Preunkert et al., 2014). On the other hand, the simulated wind speed in the surface boundary layer is in good agreement with the observations. It may consequently be argued that the turbulence schemes used in MAR (Monin-Obukhov similarity theory and the $E-\varepsilon$ model) are valid for the OPALE period. However, the question of whether this also remains true under strong radiational cooling, as encountered during winter at Dome $\mathrm{C}$, is still open.

Consequently, model outputs and especially their turbulent characteristics are useful when interpreting the observations made in the case of observed clear sky during OPALE. Indeed, clear sky conditions, i.e. situations for which the model simulation is in excellent agreement with available observations, are more adequate when discussing measurements of species involved in photochemical processes. In particular, the good behaviour of the simulated surface turbulent fluxes allows us to use the associated turbulent eddy diffusivity coefficient to evaluate the impact of turbulent transport on $\mathrm{NO}_{x}$, $\mathrm{HONO}$ and $\mathrm{HCHO}$ emitted from snow. In addition, the simulated boundary layer height indicates over which thickness of the atmosphere these chemical species are diluted. In brief, the use of such a model will allow us to optimize the experimental set-up for future campaigns aiming to characterize the low troposphere chemistry at Dome C.

Acknowledgements. The OPALE project was funded by ANR (Agence National de Recherche) contract ANR-09-BLAN0226. Most of the computations presented in this paper were performed using the Froggy platform of the CIMENT infrastructure (https://ciment.ujf-grenoble.fr), which is supported by the Rhône-Alpes region (grant CPER07_13 CIRA), the OSUG@2020 labex (reference ANR10 LABX56) and the Equip@ Meso project (reference ANR-10-EQPX-29-01) of the Investissements d'Avenir programme supervised by the Agence Nationale pour la Recherche. This work was also granted access to the HPC resources of [TGCC/CINES/IDRIS] under the allocation 2014-1523 made by GENCI. The IPEV-CALVA, IPEV-CESOA, INSU-LEFE-CLAPA and OSUG GLACIOCLIM-CENACLAM projects are acknowledged for their support. ABLCLIMAT research was supported by the Italian National Research Programme (PNRA) in the framework of French-Italian projects for Dome C.

Edited by: T. Bartels-Rausch

\section{References}

Andreas, E. L.: Physically based model of the form drag associated with sastrugi. US Army Cold Regions Research and Engineering Laboratory, Hanover, NH, CRREL Report No CR 95-16, 12 pp., 1995.

Argentini, S. and Pietroni, I.: An Integrated Observing System for Boundary Layer Monitoring at Concordia Station, Antarctica, in: Integrated Ground-Based Observing Systems, edited by: Cimini, D., Marzano, F., and Visconti, G., Springer-Verlag, Berlin Heidelberg, 199-208, 2010.

Argentini, S., Pietroni, I., Mastrantonio, G., Petenko, I., and Viola, A.: Use of a high-resolution sodar to study surface-layer turbulence at night, Bound.-Lay. Meteorol., 143, 177-188, 2011.

Argentini, S., Petenko, I., Viola, A., Mastrantonio, G., Pietroni, I., Casasanta, G., Aristidi, E., and Genthon, C.: The surface layer observed by a high-resolution sodar at DOME C, Antarctica, Ann. Geophys.-Italy, 56, F0557, doi:10.4401/ag-6347, 2013.

Bintanja, R.: Snowdrift suspension and atmospheric turbulence. Part I: Theoretical background and model description, Bound.Lay. Meteorol., 95, 343-368, 2000.

Brun, E., Six, D., Picard, G., Vionnet, V., Arnaud, L., Bazile, E., Boone, A., Bouchard, A., Genthon, C., Guidard, V., Le Moigne, P., Rabier, F., and Seity, Y.: Snow/atmosphere coupled simulation at Dome C, Antarctica, J. Glaciol., 52, 721-736, 2011.

Casasanta, G., Pietroni, I., Petenko, I., and Argentini, S.: Observed and Modelled Convective Mixing-Layer Height at Dome C, Antarctica, Bound.-Lay. Meteorol., 151, 597-608, doi:10.1007/s10546-014-9907-5, 2014.

Cassano, J. J. and Parish, T. R.: An analysis of the nonhydrostatic dynamics in numerically simulated Antarctic katabatic flows, J. Atmos. Sci, 57, 891-898, 2000.

Dee, D. P., Uppala, S. M., Simmons, A. J., Berrisford, P., Poli, P., Kobayashi, S., Andrae, U., Balmaseda, M. A., Balsamo, G., Bauer, P., Bechtold, P., Beljaars, A. C. M., van de Berg, L., Bidlot, J., Bormann, N., Delsol, C., Dragani, R., Fuentes, M., Geer, A. J., Haimberger, L., Healy, S. B., Hersbach, H., Hólm, E. V., Isaksen, L., Kållberg, P., Köhler, M., Matricardi, M., McNally, A. P., Monge-Sanz, B. M., Morcrette, J.-J., Park, B.-K., Peubey, C., de Rosnay, P., Tavolato, C., Thépaut, J.-N., and Vitart, F.: The ERA-Interim reanalysis: configuration and performance of the data assimilation system, Q. J. Roy. Meteorol. Soc., 137, 553597, doi:10.1002/qj.828, 2011.

De Ridder, K. and Gallée, H.: Land Surface-Induced Regional Climate Change in Southern Israel, J. Appl. Meteorol., 37, 1470-1485, doi:10.1175/15200450(1998)037<1470:LSIRCC>2.0.CO;2, 1998.

Dommergue, A., Barret, M., Courteaud, J., Cristofanelli, P., Ferrari, C. P., and Gallée, H.: Dynamic recycling of gaseous elemental mercury in the boundary layer of the Antarctic Plateau, Atmos. Chem. Phys., 12, 11027-11036, doi:10.5194/acp-1211027-2012, 2012.

Duynkerke, P. G. and Driedonks, A. G. M.: A model for the turbulent structure of the stratocumulus-topped atmospheric boundary layer, J. Atmos. Sci., 44, 43-64, 1987.

Duynkerke, P. G.: Application of the $E--\epsilon$ Turbulence Closure Model to the Neutral and Stable Atmospheric Boundary Layer, J. Atmos. Sci., 45, 865-880, 1988.

EPICA community members: Eight glacial cycles from an Antarctic ice core, Nature, 429, 623-628, 2004. 
Fettweis, X., Gallée, H., Lefebre, F., and Van Ypersele, J.: Greenland Surface Mass Balance simulated by a Regional Climate Model and Comparison with satellite derived data in 1990-1991, Clim. Dynam., 24, 623-640, doi:10.1007/s00382-005-0010-y, 2005.

Frey, M. M., Brough, N., France, J. L., Anderson, P. S., Traulle, O., King, M. D., Jones, A. E., Wolff, E. W., and Savarino, J.: The diurnal variability of atmospheric nitrogen oxides (NO and $\mathrm{NO}_{2}$ ) above the Antarctic Plateau driven by atmospheric stability and snow emissions, Atmos. Chem. Phys., 13, 3045-3062, doi:10.5194/acp-13-3045-2013, 2013.

Frey, M. M., Roscoe, H. K., Kukui, A., Savarino, J., France, J. L., King, M. D., Legrand, M., and Preunkert, S.: Atmospheric nitrogen oxides ( $\mathrm{NO}$ and $\mathrm{NO}_{2}$ ) at Dome $\mathrm{C}$, East Antarctica, during the OPALE campaign, Atmos. Chem. Phys. Discuss., 14, 3128131317, doi:10.5194/acpd-14-31281-2014, 2014.

Gallée, H. and Schayes, G.: Development of a Three-Dimensional Meso-gamma Primitive Equations Model, Katabatic Winds Simulation in the area of Terra Nova Bay, Antarctica, Mon. Weather Rev., 122, 671-685, 1994.

Gallée, H.: Simulation of the mesocyclonic activity in the Ross Sea, Antarctica, Mon. Weather Rev., 123, 2051-2069, 1995.

Gallée, H., Guyomarc'h, G., and Brun, E.: Impact of Snow Drift on the Antarctic Ice Sheet Surface Mass Balance. Possible Sensitivity to Snow Surface Properties, Bound.-Lay. Meterorol., 99, 1-19, 2001.

Gallée, H. and Gorodetskaya, I.: Validation of a limited area model over Dome C, Antarctic Plateau, during winter, Clim. Dynam., 23, 61-72, doi:10.1007/s00382-008-0499-y, 2010.

Gallée, H., Trouvilliez, A., Agosta, C., Genthon, C., Favier, V., and Naaim-Bouvet, F.: Transport of snow by the wind: a comparison between observations made in Adélie Land, Antarctica, and simulations made with the Regional Climate Model MAR, Bound.Lay. Meteorol., 146, 133-147, doi:10.1007/s10546-012-9764-z, 2013.

Gallée, H., Barral, H., Vignon, E., and Genthon, C.: A case study of a low-level jet during OPALE, Atmos. Chem. Phys., 15, 62376246, doi:10.5194/acp-15-6237-2015, 2015.

Genthon, C., Town, M. S., Six, D., Favier, V., Argentini, S., and Pellegrini, A.: Meteorological atmospheric boundary layer measurements and ECMWF analyses during summer at Dome C, Antarctica, J. Geophys. Res.-Atmos., 115, D05104, doi:10.1029/2009JD012741, 2010.

Genthon, C., Six, D., Favier, V., Lazzara, M., and Keller, L.: Atmospheric temperature measurement biases on the Antarctic plateau, J. Atmos. Oceanic Technol., 12, 1598-1605, doi:10.1175/JTECH-D-11-00095.1, 2011.

Genthon, C., Six, D., Gallée, H., Grigioni, P., and Pellegrini, P.: Two years of atmospheric boundary layer observations on a 45$\mathrm{m}$ tower at Dome C on the Antarctic plateau, J. Geophys. Res.Atmos., 118, 3218-3232, doi:10.1002/jgrd.50128, 2013.

Kaimal, J. C. and Finnigan, J. J.: Atmospheric Boundary-Layer Flows: Their Structure and Measurement, 289 pp., Oxford University Press, 1994.

Kerbrat, M., Legrand, M., Preunkert, S., Gallée, H., and Kleffmann, J.: Nitrous Acid at Concordia on the East Antarctic Plateau and its transport to the coastal site of Dumont d'Urville, J. Geophys. Res., 117, D08303, doi:10.1029/2011JD017149, 2012.
King, J. C. and Anderson, P. S.: Heat and water vapour fluxes and scalar roughness lengths over an Antarctic ice shelf, Bound.-Lay. Meteorol., 69, 101-121, 1994.

King, J. C., Argentini, S., and Anderson, P. S.: Contrasts between the summertime surface energy balance and boundary layer structure at Dome C and Halley stations, Antarctica, J. Geophys. Res.-Atmos., 111, 1-13, doi:10.1029/2005JD006130, 2006.

Kukui, A., Legrand, M., Preunkert, S., Frey, M. M., Loisil, R., Gil Roca, J., Jourdain, B., King, M. D., France, J. L., and Ancellet, G.: Measurements of $\mathrm{OH}$ and $\mathrm{RO}_{2}$ radicals at Dome C, East Antarctica, Atmos. Chem. Phys., 14, 12373-12392, doi:10.5194/acp-14-12373-2014, 2014.

Lascaux, F., Masciadri, E., and Hagelin, S.: Mesoscale optical turbulence simulations above Dome C, Dome A and South Pole, Mon. Not. R. Astron. Soc., 411, 693-704, doi:10.1111/j.13652966.2010.17709.x, 2011.

Lefebre, F., Fettweis, X., Gallée, H., Van Ypersele, J., Marbaix, P., Greuell, W., and Calanca, P.: Evaluation of a high-resolution regional climate simulation over Greenland, Clim. Dynam., 25, 99-116, doi:10.1007/s00382-005-0005-8, 2005.

Legrand, M., Preunkert, S., Jourdain, B., Gallée, H., Goutail, F., Weller R., and Savarino, J.: Year round record of surface ozone at coastal (Dumont d'Urville) and inland (Concordia) sites in East Antarctica, J. Geophys. Res., 114, D20306, doi:10.1029/2008JD011667, 2009.

Legrand, M., Preunkert, S., Frey, M., Bartels-Rausch, Th., Kukui, A., King, M. D., Savarino, J., Kerbrat, M., and Jourdain, B.: Large mixing ratios of atmospheric nitrous acid (HONO) at Concordia (East Antarctic Plateau) in summer: a strong source from surface snow?, Atmos. Chem. Phys., 14, 9963-9976, doi:10.5194/acp-14-9963-2014, 2014.

Marbaix, P., Gallée, H., Brasseur, O., and Van Ypersele, J.: Lateral Boundary Conditions in regional climate models: a detailed study of the relaxation procedure, Mon. Weather Rev., 131, 461479, 2003.

Morcrette, J.-J.: Assessment of the ECMWF model cloudiness and surface radiation fields at the ARM-SGP site, Mon. Weather Rev., 130, 257-277, 2002.

Nash, J. E. and Sutcliffe, J. V.: River flow forecasting through conceptual models part I A discussion of principles, J. Hydrol., 10, 282-290, doi:10.1016/0022-1694(70)90255-6, 1970.

Pietroni, I., Argentini, S., and Petenko, I.: One Year of SurfaceBased Temperature Inversions at Dome C, Antarctica, Bound.Lay. Meteorol., 150, 131-151, doi:10.1007/s10546-013-9861-7, 2014.

Preunkert, S., Legrand, M., Frey, M., Kukui, A., Savarino, J., Gallée, H., King, M., Jourdain, B., Vicars, W., and Helmig, D.: Formaldehyde (HCHO) in air, snow and interstitial air at Concordia (East Antarctic plateau) in summer, Atmos. Chem. Phys. Discuss., 14, 32027-32070, doi:10.5194/acpd-14-32027-2014, 2014.

Sadibekova, T., Fossat, E., Genthon, C., Krinner, G., Aristidi, E., Agabi, K., and Azouit, M.: On the atmosphere for astronomers above Dome C, Antarctica, Antarctic Sci,, 18, 437-444, 2006.

Sukoriansky, S., Galperin, P., and Veniamin, P.: Application of a new spectral theory on stably stratified turbulence to the atmospheric boundary layer over sea ice, Bound.-Lay. Meteorol., 117, 231-257, 2005. 
Swain, M. R. and Gallée, H.: Antarctic Boundary Layer Seeing, Astr. Soc. P, 118, 1190-1197, 2006.

Van As, D., van den Broeke, M. R., and Helsen, M. M.: Structure and dynamics of the summertime atmospheric boundary layer over the Antarctic plateau, I: Measurements and model validation, J. Geophys. Res., 111, D007102, doi:10.1029/2005JD005948, 2006.

Van Dijk, A., Moen, A., and de Bruin, H.: The principles of surface flux physics: theory, practice and description of the ECPACK library. Internal report 2004/1, Meteorology and Air Quality Group, Wageningen University, Wageningen, The Netherlands, 2006.
Walden, V. P., Warren, S. G., and Tuttle, E.: Atmospheric Ice Crystals over the Antarctic Plateau in Winter, J. Appl. Meteorol., 42, 1391-1405, 2003.

Wamser, C. and Lykossov, V. N.: On the Friction Velocity during Blowing Snow, Beitr. Phys. Atmosph., 68, 85-94, 1995.

Wendler, G. and Kelley, J.: On the albedo of snow in Antarctica: a contribution to I.A.G.O., J. Glaciol., 34, 19-25, 1988. 